\title{
Emergency nurses' Knowledge and Practice Regarding Preparedness of Disaster Management at a University Hospital. Egypt
}

\author{
Khalil NS ${ }^{*}$, Ahmed Atia SM${ }^{2}$, Moustafa $\mathrm{MF}^{3}$ and Hafez Soliman TT4 \\ ${ }^{1}$ Department of Critical Care and Emergency Nursing, Faculty of Nursing, Cairo \\ University, Egypt \\ ${ }^{2}$ Department of Vascular Surgery, Manager of Mansoura Emergency Hospital, Faculty of \\ Medicine, Mansoura University, Egypt
}

\section{Review Article \\ Volume 3 Issue 3}

Received Date: May 14, 2019

Published Date: June 04, 2019

DOI: $10.23880 /$ nhij-16000192

${ }^{3}$ Department of Critical Care and Emergency Nursing, Faculty of Nursing, Mansoura University, Egypt

${ }^{4}$ Department of Critical Care and Emergency Nursing, Faculty of Nursing, Port-Said University, Egypt

*Corresponding author: Nahla Khalil, Department of Critical Care and Emergency Nursing, Faculty of Nursing, Cairo University, Egypt, Tel: 1066225938; Email: nahlakhalil28@yahoo.com

\section{Abstract}

Background: A disaster is an incident that causes massive destruction. Nurses role is very essential in disaster management.

The aim of the study: Was to assess emergency nurses' knowledge and practices regarding preparedness of disaster management.

Subject and Methods: A cross-sectional study was conducted in the emergency department at Mansoura emergency hospital to collect data from 22 emergency nurses. Two tools were used, first; a disaster structured questionnaire and the second tool was about disaster nursing performance observational checklist.

Results: It revealed that more than two thirds (72.7\%) of nurses have got unsatisfactory level of knowledge regarding preparedness of disaster management with the mean knowledge score $10.32 \pm 2.75$ out of 15 score. Concerning nurses' practices, the nurses demonstrated satisfactory practices regarding the process of patient's admission. On the other hand, they showed unsatisfactory practices regarding triage care, utilizing personal protective equipment and infection control measures. significant positive correlations were found between nurses' knowledge and experience in the emergency department, as well as attending previous courses related to disaster preparedness \& total practice

Conclusion and Recommendation: The overall level of knowledge and practice were unsatisfactory regarding preparedness of disaster management -It can be recommended that emergency nurses need integration of clearly titled 


\section{Nursing \& Healthcare International Journal}

theory and practice, teaching courses about disaster and emergency preparedness into nursing curricula are crucial needed and provided in respect to their training preferences.

Keywords: Knowledge; Practice Preparedness; Disaster Management

\section{Introduction}

Large scale disasters around the world demonstrate that no one and no country is immune from the threat of natural or other tragedies [1]. Disasters occur every day somewhere in the world with dramatic impact on individuals, families and communities [2]. The first decade of the twenty first century had considerably raised an awareness of the potential danger to modern civilization from disasters, both natural and manmade [3].

Disasters can classify to natural and manmade, natural disasters arise from forces of nature and include earthquakes volcanic eruptions, hurricanes, floods, fire, and tornadoes. In addition infectious disasters can be classified as epidemic or pandemic [4]. Manmade disasters are due to identifiable human causes and may be further classified as complex emergencies (e.g. wars, terrorist attacks) and technological disasters (e.g., industrial accidents, explosions from hazardous material) [5].

Emergency preparedness is comprehensive skills, abilities, knowledge, and actions that are needed to respond and prepare for a threat, actual or suspected, chemical, radiological, nuclear, biological, or explosive in nature [6]. During major disaster events, the demand for nursing staff is much greater than the demands for any other healthcare professionals [7]. Nurses should anticipate an expanded role during disaster events to include caring for the sick and injured, infection control, contingency planning to prevent further damage, triage, mass immunizations, mass evacuations, and treatment for mass casualties [8].

\section{Aim of study}

The aim of this study is to assess emergency nurses' knowledge and practice regarding preparedness of disaster management.

\section{Subjects and Methods}

A descriptive research design was utilized in the current study. The study was conducted in the emergency department at Mansoura emergency hospital. The emergency department consisted of 8 emergency rooms
(2 medical rooms, 2 surgical rooms, 2 accident rooms and 2 treatment rooms in addition to 1 medical recovery room, 1 surgical recovery room, 1 poisoning treatment room, 1 orthopedic room, 1 x-ray and 1 CT room, it receives patients from emergency days of the hospital. A convenience sample was obtained from 22 emergency nurses with various ages, sexes and years of experience and level of educations who worked during disaster in the emergency days (Sunday, Tuesday and Thursday).

\section{Tools}

Two tools were developed and utilized by the researcher for data collection, after reviewing the related literatures [9-12].

Tool I: Disaster Knowledge Structured Questionnaire: It was consisted of two parts:

\section{Part 1: Nurses' Demographic Data:}

It included questions related to the emergency nurses' demographic data such as: name, age, sex, academic qualifications, years of experience in emergency department and attending training program regarding disasters preparedness.

\section{Part 2: Disaster Nurses' Knowledge Questionnaire:}

It composed of 15 questions in relation to preparedness of disaster management in the form of multiple choice questions (MCQ) such as: Definition of disaster (1 item), Types of disaster (2 items), Causes of disaster (3 items), Management of disaster (3 items) and Role of hospital and emergency nurse during disaster (6 items). The Scoring system of the nurses' knowledge questionnaire distributed as follows; each correct answer scored 1 mark and each incorrect answer scored zero. Total score for knowledge was 15 point. A higher score indicated a greater nurse's knowledge. Knowledge score was categorized as follows: Scores less than $85 \%$ (less than 12.75 mark) was considered unsatisfactory and the scores equal or more than $85 \%$ (equal or more than 12.75 marks) considered satisfactory $[13,14]$.

\section{Tool II: Disaster Nurses' Performance Observational Checklist:}

It was developed by the researchers to assess emergency nurses' practices regarding preparedness of disaster management in the emergency department; it 


\section{Nursing \& Healthcare International Journal}

included 36 items covering the following points: Patient admission (How to admit patients in disaster management?) (4 items) using a triage during the care of patients in disaster management (14 items) and using universal precautions during giving care to patients in disaster management (18 items). The Scoring system of the nurses' practices were distributed follows as; each step done complete and correct was given 2 scores, each step done incomplete was given 1 score and not done steps scored zero. The total scores of practice were 72 marks. Practice score was categorized as follows: Scores less than 85\% (less than 61.2 marks) was considered unsatisfactory and the scores equal or more than $85 \%$ (equal or more than 61.2 marks) considered satisfactory $[13,14]$.

\section{Data Collection Procedure}

An explanation about the aim and the nature of the study was discussed with nurse's staff in the emergency unit. Emergency nurses' knowledge about disaster preparedness was assessed using interviewing questionnaire in the non-emergency day (using tool I, part with each emergency nurse. Questionnaire was done individually; complete instructions regarding answering the questionnaire sheet were given to the emergency nurses. The average time for completing the questionnaire sheet ranged from 10-15 minutes. Assessment of emergency nurses' practice during disaster management was done for each one while worked with the patients through observational checklist using (tool II).

\section{Legal and Ethical Considerations}

The research ethical committee permission to conduct the study was obtained from the hospital administrative authority after explaining the aim and the nature of the study , Faculty of Nursing , Mansoura University to accomplish this study, verbal consent was obtained from emergency nurses, the purpose of the study was explained to the emergency nurses, reassurance was given to the emergency nurses about confidentiality of their responses and nurses were informed that they had the right to withdraw at any time from the study. All data and information obtained were protected through coding to ensure confidentiality.

\section{Procedure of Data Collection}

Two phases: the preparatory and implementation phase Phase I: preparatory phase:

This phase involved preparation of data collection tools based on reviewing current, national and international studies. The tools were developed by the researcher and tested for validity and reliability.

\section{Validity and Reliability}

Tools were developed by the researcher after reviewing the relevant literature and tested for its validity by jury of 5 expertises in the field of emergency and their recommended modifications had been done. The reliability of the tools was tested by using the Cronbach' Alpha test in SPSS as the following: The Cronbach's Alpha formula was 0.67 for knowledge questionnaire and The Cronbach's Alpha formula was 0.90 for disaster nurses' performance observational checklist.

\section{Pilot Study}

The pilot study was conducted on $10 \%$ of the emergency nurses who were selected randomly from the same setting then excluded from the studying sample, on the other hand 5 nurses were excluded from the study because they refuse to participate. The purposes of the pilot study were to ascertain the clarity and applicability of the tool to estimate the time needed to answer the questionnaire and to identify any possible obstacles that may hinder data collection.

\section{Phase II: Implementation phase:}

The researcher visited the emergency hospital (ER) at the morning shift from 8am-to-2pm on all emergency hospital days (Sunday, Tuesday, Thursday) to check for any disaster and contact with some emergency head nurses and hospital members who work in ER to be informed about any disaster that may occur on these days. The study disaster was fire accident due to the explosion of a gas stove which consisted of 22 emergent cases arrived to emergency unit in the morning shift on Thursday 6/9/2018. The ages of the injured ranged from 6 years to 75 years with varying degrees of burns. 10 cases were discharged after their condition improved. The other 12 cases were transferred to ICU where the acute care was provided to them and the other 2 cases were transferred to the center for burns and beauty due to their critical condition and their increased severity.

\section{Data Analysis}

The raw data were, sorted, coded, and analyzed using SPSS system files (SPSS package version 18). Analysis and interpretation of data were conducted. The following statistical measures were used: Data were fed to the computer and analyzed using IBM SPSS software package version 20.0. (Armonk, NY: IBM Corp) descriptive data 
were described using number and percent. Quantitative data were described using range (minimum and maximum), mean, and standard deviation. Significance of the obtained results was judged at 0.05 levels. T- Test was used to compare between two studied groups in relation to knowledge score. Moreover, F-test (ANOVA) was used to compare between more than two groups of nurses. In addition Pearson coefficient was utilized to correlate between two normally distributed quantitative variables such as knowledge, practice and selected demographic variables.

\section{Results}

\begin{tabular}{|c|c|c|}
\hline Nurses Demographic Data & No. & $\%$ \\
\hline \multicolumn{3}{|l|}{ Age } \\
\hline $26-35$ & 15 & 68.2 \\
\hline $36-45$ & 3 & 13.6 \\
\hline$\geq 46$ & 4 & 18.2 \\
\hline Mean \pm SD. & \multicolumn{2}{|c|}{$34.18 \pm 7.22$} \\
\hline \multicolumn{3}{|l|}{ Gender } \\
\hline Male & 8 & 36.4 \\
\hline Female & 14 & 63.6 \\
\hline \multicolumn{3}{|l|}{ Marital status } \\
\hline Single & 6 & 27.3 \\
\hline Married & 16 & 72.7 \\
\hline \multicolumn{3}{|l|}{ Current position } \\
\hline Nurse staff & 16 & 72.7 \\
\hline Head of nursing & 6 & 27.3 \\
\hline \multicolumn{3}{|l|}{ Academic qualifications } \\
\hline Diploma in nursing & 16 & 72.7 \\
\hline Technical health institute & 1 & 4.5 \\
\hline Bachelor of nursing & 5 & 22.7 \\
\hline \multicolumn{3}{|l|}{ Years of experience } \\
\hline Less than 5 years & 2 & 9.1 \\
\hline 5-10years & 7 & 31.8 \\
\hline >10years & 13 & 59.1 \\
\hline Mean \pm SD & \multicolumn{2}{|c|}{$9.95 \pm 3.85$} \\
\hline \multicolumn{3}{|l|}{ Previous training course in disaster } \\
\hline No & 13 & 59.1 \\
\hline Yes & 9 & 40.9 \\
\hline If answer yes & & \\
\hline \multicolumn{3}{|l|}{ Duration of course $(n=9)$} \\
\hline Day & 1 & 11.1 \\
\hline 3days & 1 & 11.1 \\
\hline One weak & 6 & 66.7 \\
\hline More than one weak & 1 & 11.1 \\
\hline \multicolumn{3}{|l|}{ Number of courses $(n=9)$} \\
\hline One course & 4 & 44.4 \\
\hline Three courses & 5 & 55.6 \\
\hline
\end{tabular}

Table 1: Frequency distribution of the emergency nurses demographic data $(n=22)$. 


\section{Nursing \& Healthcare International Journal}

The selected emergency nurses 22 were studied. The statistical analysis showed that more than two third $(68.2 \%)$ of the studied emergency nurses were between 25-35 years old, two third of them (63.6\%) were female, below three forth of them (72.7\%) were married, concerning with the academic qualifications below three forth of the studied nurses were had diploma in nursing and their current positions was nurses staff, concerning with years of experience, more than half had 10 years of experience and finally more than half (59.1\%) not attending previous training course in disaster (Table 1 ).

As can be seen from Figure 1 more than two third $(72.7 \%)$ of nurses revealed un satisfactory level of knowledge regarding preparedness of disaster management with the mean knowledge score $10.32 \pm 2.75$

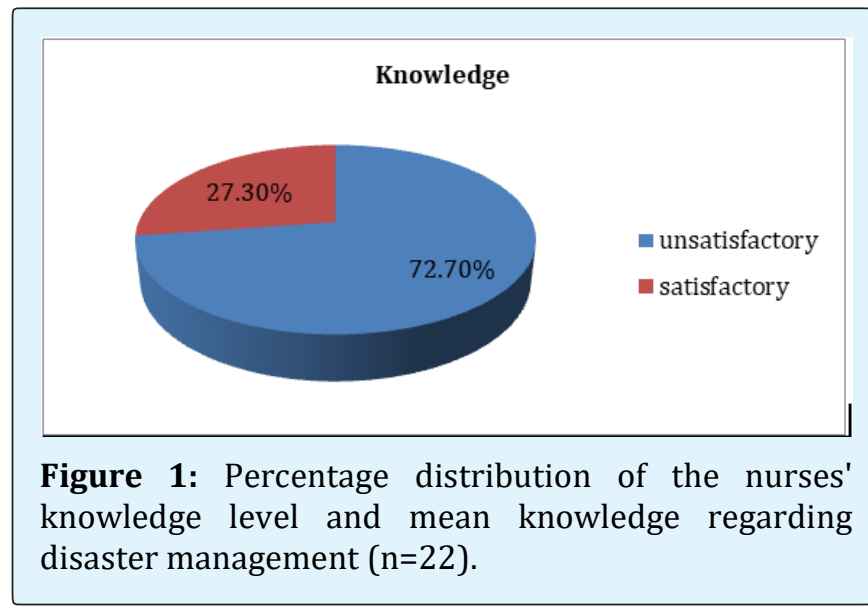
out of 15 score.

\begin{tabular}{|c|c|c|c|c|}
\hline \multirow{2}{*}{ Disaster nurse's knowledge questionnaire } & \multicolumn{2}{|c|}{ Incorrect answer } & \multicolumn{2}{|c|}{ Correct answer } \\
\hline & No. & $\%$ & No. & $\%$ \\
\hline Disaster is & 5 & 22.7 & 17 & 77.3 \\
\hline Types of disasters & 4 & 18.2 & 18 & 81.8 \\
\hline $\begin{array}{l}\text { Eruption, earthquakes, high temperature or cooler weather and heavy } \\
\text { rain caused great destruction of property and humans, and is } \\
\text { considered a kind of disaster: }\end{array}$ & 10 & 45.5 & 12 & 54.5 \\
\hline $\begin{array}{l}\text { Technological disasters are the results of the failure of use of } \\
\text { technology, such as: }\end{array}$ & 8 & 36.4 & 14 & 63.6 \\
\hline Criminal acts and stampedes, riots and war is kind of the disaster & 8 & 36.4 & 14 & 63.6 \\
\hline Joint disasters between nature and humans, such as & 14 & 63.6 & 8 & 36.4 \\
\hline The phases of disaster management & 9 & 40.9 & 13 & 59.1 \\
\hline Disaster preparedness & 8 & 36.4 & 14 & 63.6 \\
\hline Emergency plan for disaster prevention & 6 & 27.3 & 16 & 72.7 \\
\hline Emergency nurses need to increase their knowledge in & 5 & 22.7 & 17 & 77.3 \\
\hline Emergency nurse tasks & 10 & 45.5 & 12 & 54.5 \\
\hline $\begin{array}{l}\text { Emergency nurse should use of personal protective equipment (hand } \\
\text { washing, wear gloves, wear gown, wear protective head, wear } \\
\text { protective boots and a face mask) }\end{array}$ & 16 & 72.7 & 6 & 27.3 \\
\hline $\begin{array}{l}\text { Every hospital has a plan to cope with disasters, have internal } \\
\text { guidelines }\end{array}$ & 0 & 0 & 22 & 100 \\
\hline When confirm the occurrence of disaster & 0 & 0 & 22 & 100 \\
\hline One of the disaster management barriers & 0 & 0 & 22 & 100 \\
\hline
\end{tabular}

Table 2: Frequency distribution of the emergency nurses correct/in correct answers regarding knowledge questions related to preparedness of disaster management $(n=22)$.

As can be seen from Table 2 showed that all the studied emergency nurses (100\%) gave correct answer in the following items related to every hospital has a plan to cope with disasters, have internal guidelines, when confirm the occurrence of disaster, one of the disaster management barriers, moreover, more than three forth $(81.8 \%)$ gave correct answer regarding types of disasters, on the other hand more than two third reported incorrect answer pertinent to the time for emergency nurse to use of personal protective equipment (hand washing, wear gloves, wear gown, wear protective head, wear protective boots and a face mask) finally less than quarter (18.2\%) reported incorrect answer pertinent to types of disasters. 


\section{Nursing \& Healthcare International Journal}

\begin{tabular}{|l|c|c|c|c|c|c|}
\hline \multicolumn{1}{|c|}{$\begin{array}{c}\text { Disaster nursing performance observational } \\
\text { checklist }\end{array}$} & \multicolumn{2}{c|}{ Not done } & \multicolumn{2}{c|}{$\begin{array}{c}\text { Done incorrect/ } \\
\text { incomplete }\end{array}$} & \multicolumn{2}{c|}{$\begin{array}{c}\text { Done correct / } \\
\text { complete }\end{array}$} \\
\cline { 2 - 6 } & No. & $\mathbf{\%}$ & No. & \% & No. & \% \\
\hline How to receive disaster patient & & & & & & \\
\hline $\begin{array}{l}\text { Obtain informed consent from the patient or family } \\
\text { before beginning care }\end{array}$ & 0 & 0 & 0 & 0 & 22 & 100 \\
\hline Assess situation. & 0 & 0 & 0 & 0 & 22 & 100 \\
\hline Ensure that emergent patients receive care immediately. & 0 & 0 & 0 & 0 & 22 & 100 \\
\hline $\begin{array}{l}\text { Ensure that urgent patients receive care within 30 min to } \\
\text { 2 hrs. }\end{array}$ & 0 & 0 & 0 & 0 & 22 & 100 \\
\hline Triage & & & & & & \\
\hline Take vital signs & 0 & 0 & 0 & 0 & 22 & 100 \\
\hline $\begin{array}{l}\text { Take complete history from the patient or from the } \\
\text { patient's family }\end{array}$ & 0 & 0 & 0 & 0 & 22 & 100 \\
\hline Do head to toe assessment. & 0 & 0 & 0 & 0 & 22 & 100 \\
\hline Take diagnostic test. & 0 & 0 & 0 & 0 & 22 & 100 \\
\hline Take laboratory test. & 0 & 0 & 0 & 0 & 22 & 100 \\
\hline Follow the ABCD methods. & 0 & 0 & 1 & 4.5 & 21 & 95.5 \\
\hline Establish a patent airway. & 0 & 0 & 1 & 4.5 & 21 & 95.5 \\
\hline Provide adequate ventilation. & 0 & 0 & 1 & 4.5 & 21 & 95.5 \\
\hline Evaluate cardiac output. & 0 & 0 & 1 & 4.5 & 21 & 95.5 \\
\hline Determine neurological disability. & 0 & 0 & 1 & 4.5 & 21 & 95.5 \\
\hline Apply E-C-G. & 9 & 40.9 & 12 & 54.5 & 1 & 4.5 \\
\hline Apply arterial lines. & 2 & 9.1 & 10 & 45.5 & 10 & 45.5 \\
\hline Apply urinary catheter. & 19 & 86.4 & 2 & 9.1 & 1 & 4.5 \\
\hline Splinting of suspected fractures & 22 & 100 & 0 & 0 & 0 & 0 \\
\hline Cleaning of wounds. & 0 & 0 & 8 & 36.4 & 14 & 63.6 \\
\hline Dressing of wounds. & 0 & 0 & 8 & 36.4 & 14 & 63.6 \\
\hline Plan for the patient safe discharge. & 0 & 0 & 0 & 0 & 22 & 100 \\
\hline Plan for follow up care. & 0 & 0 & 0 & 0 & 22 & 100 \\
\hline
\end{tabular}

Table 3: Frequency distribution of nurse's correct/incorrect/not done practice regarding preparedness of disaster management $(\mathrm{n}=22)$.

As can be seen from Table 3 that all the studied emergency nurses $(100 \%)$ demonstrated correct practice regarding admit patient in disaster, take vital signs, take complete history from the patient or from the patient's family, do head to toe assessment, take diagnostic test, take laboratory test, plan for the patient safe discharge \& plan for follow up care, on the other hand more than half (54.5\%) of the studied emergency nurses demonstrated in complete practice regarding apply E-C-G, also most of nurses (86.4) were not inserted urinary catheter and all of them $(100 \%)$ were not splinting of suspected fractures .

As can be seen from Table 4 that all the studied emergency nurses $(100 \%)$ demonstrated correct practice regarding placing needles in sharp's containers, on the other hand more than three forth $(77.3 \%)$ demonstrated in correct practice regarding hand hygiene measures after removing gloves more over less than quarter $(27.3 \%)$ demonstrated in correct practice regarding changing gloves before going to another patient and changing gloves when torn or heavily contaminated and also all the studied emergency nurses (100\%) demonstrated not done practice regarding wearing protective eye when direct contact with the patient, wearing mask when direct contact with the patient, wearing gown or apron when direct contact with the patient, wearing overhead, wearing over shoes, not recapping needles after using, using syringes with retractable needle, using syringes with protective shield, using sables with protective shield, using intravenous annulation with retractable needle. 


\begin{tabular}{|l|c|c|c|c|c|c|}
\hline \multirow{2}{*}{ Disaster nursing performance observational checklist } & \multicolumn{2}{|c|}{ Not done } & \multicolumn{2}{c|}{$\begin{array}{c}\text { Done incorrect / } \\
\text { incomplete }\end{array}$} & $\begin{array}{c}\text { Done correct / } \\
\text { complete }\end{array}$ \\
\cline { 2 - 7 } & No. & $\mathbf{\%}$ & No. & $\mathbf{\%}$ & No. & \% \\
\hline Personal protective equipment and infection control measures: & & & & & & \\
\hline Hand hygiene measures before starting the working activity. & 10 & 45.5 & 12 & 54.5 & 0 & 0 \\
\hline Hand hygiene measures before going to another patient. & 10 & 45.5 & 12 & 54.5 & 0 & 0 \\
\hline Wearing gloves when direct contact with the patient. & 1 & 4.5 & 9 & 40.9 & 12 & 54.5 \\
\hline Hand hygiene measures before wearing gloves. & 9 & 40.9 & 13 & 59.1 & 0 & 0 \\
\hline Hand hygiene measures after removing gloves. & 4 & 18.2 & 17 & 77.3 & 1 & 4.5 \\
\hline Changing gloves before going to another patient. & 4 & 18.2 & 6 & 27.3 & 12 & 54.5 \\
\hline Changing gloves when torn or heavily contaminated. & 4 & 18.2 & 6 & 27.3 & 12 & 54.5 \\
\hline Wearing protective eye when direct contact with the patient. & 22 & 100 & 0 & 0 & 0 & 0 \\
\hline Wearing mask when direct contact with the patient. & 22 & 100 & 0 & 0 & 0 & 0 \\
\hline Wearing gown or upon when direct contact with the patient. & 22 & 100 & 0 & 0 & 0 & 0 \\
\hline Wearing overhead. & 22 & 100 & 0 & 0 & 0 & 0 \\
\hline Wearing over shoes. & 22 & 100 & 0 & 0 & 0 & 0 \\
\hline Not recapping needles after using. & 22 & 100 & 0 & 0 & 0 & 0 \\
\hline Placing needles in sharp's containers. & 0 & 0 & 0 & 0 & 22 & 100 \\
\hline Using syringes with retractable needle. & 22 & 100 & 0 & 0 & 0 & 0 \\
\hline Using syringes with protective shield. & 22 & 100 & 0 & 0 & 0 & 0 \\
\hline Using sables with protective shield. & 22 & 100 & 0 & 0 & 0 & 0 \\
\hline Using intravenous annulation with retractable needle. & 22 & 100 & 0 & 0 & 0 & 0 \\
\hline
\end{tabular}

Table 4: Frequency distribution of nurse's correct/incorrect/not done practice regarding preparedness of disaster management "continue" ( $\mathrm{n}=22)$.

\begin{tabular}{|c|c|c|c|c|}
\hline \multirow{2}{*}{ Action step } & \multicolumn{2}{|c|}{$<\mathbf{8 5 \%}$ unsatisfactory } & \multicolumn{2}{|c|}{$\geq \mathbf{8 5 \%}$ satisfactory } \\
\cline { 2 - 5 } & $\mathbf{N o}$ & $\mathbf{\%}$ & $\mathbf{N o}$ & $\mathbf{\%}$ \\
\hline Receive the patient & 0 & 0 & 22 & 100 \\
\hline Triage & 14 & 63.6 & 8 & 36.4 \\
\hline Personal protective measures & 22 & 100 & 0 & 0 \\
\hline Overall practice & $\mathbf{2 2}$ & $\mathbf{1 0 0}$ & $\mathbf{0}$ & $\mathbf{0}$ \\
\hline
\end{tabular}

Table 5: Frequency distribution of emergency nurse's practice level in disaster management $(n=22)$.

It is apparent from Table 5 that all nurses did not perform or apply personal protective practices while all of the nurses showed satisfactory level regarding admission of the patient.

\begin{tabular}{|c|c|}
\hline \multirow{2}{*}{ Action step } & Total score \\
\cline { 2 - 2 } & Mean \pm SD. \\
\hline Receive & $8.0 \pm 0.0$ \\
\hline Triage & $29.23 \pm 1.88$ \\
\hline Personal protective & $8.27 \pm 3.01$ \\
\hline Overall practice & $45.50 \pm 4.18$ \\
\hline
\end{tabular}

Table 6: Mean and standard deviation of sub and overall practices regarding performance in disaster management $(n=22)$.

It is apparent from Table 6 all nurses showed high mean scores regarding admission of the patient, on the other hand the table showed low mean practice scores regarding applying personal protective measures while working with the patient.

\begin{tabular}{|c|c|c|}
\hline \multirow{2}{*}{ Practices score } & \multicolumn{2}{|c|}{ Knowledge score } \\
\cline { 2 - 3 } & $\mathbf{r}$ & $\mathbf{p}$ \\
\hline Receiving a disaster patient score & 0 & 1 \\
\hline Triage score & 0.401 & 0.064 \\
\hline $\begin{array}{c}\text { Personal protective equipment and } \\
\text { infection control measures score }\end{array}$ & 0.018 & 0.937 \\
\hline Total practice score & 0.193 & 0.391 \\
\hline
\end{tabular}

Table 7: Correlation between mean knowledge scores and mean practices scores regarding preparedness of disaster management among the studied emergency nurses.

Correlation between mean knowledge scores and mean practices scores regarding preparedness of disaster 
management among the studied emergency nurses shows that there is positive correlation between knowledge and practice scores regarding patient's admission only, moreover no significant correlation were found between the total knowledge and the total practice $\operatorname{scores}(\mathrm{R}=0.1, \mathrm{P}=0.3)$ (Table 7).

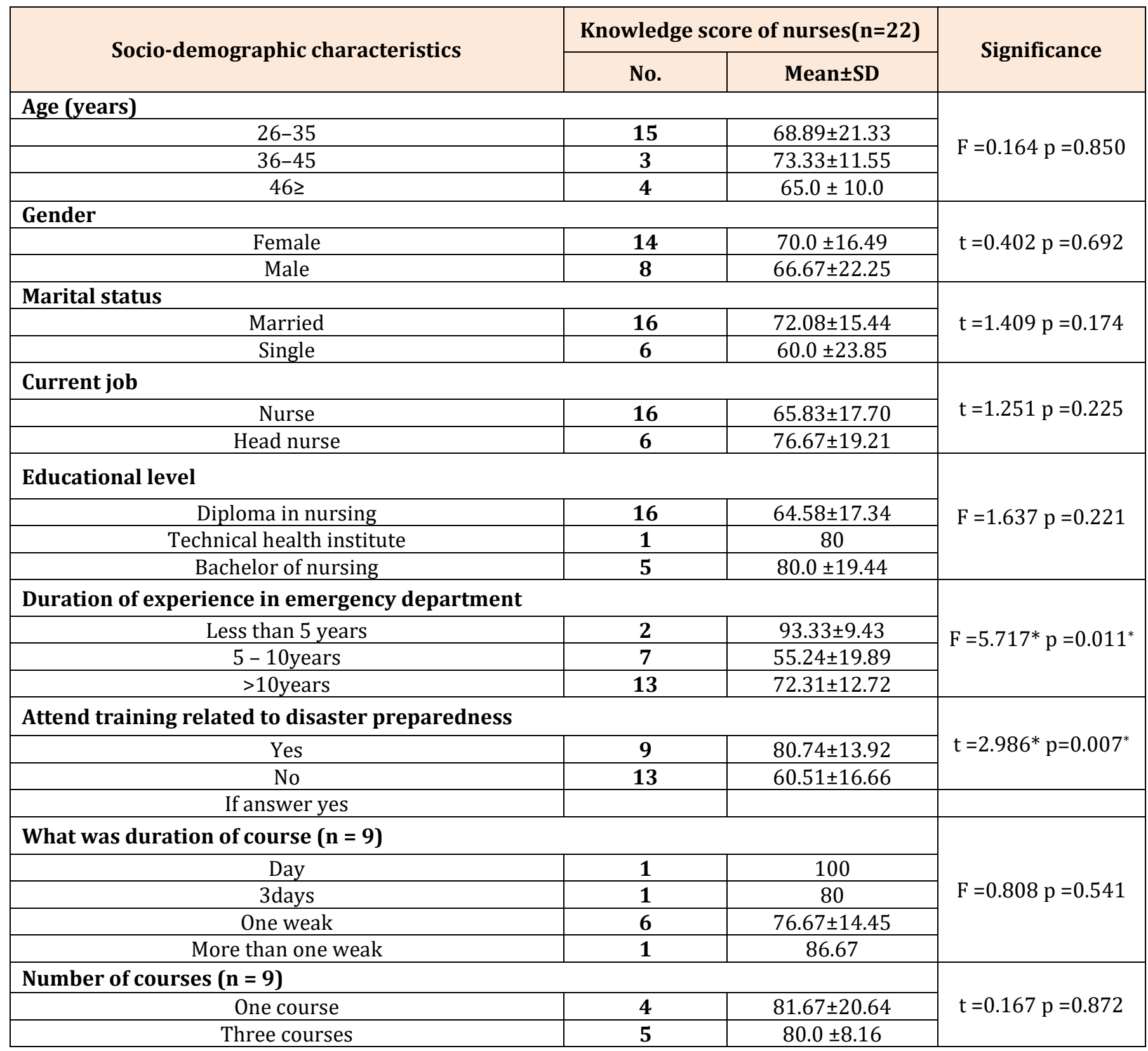

Table 8: Comparison of knowledge scores among the emergency nurses regarding preparedness of disaster management by their demographic characteristics.

Comparison of knowledge scores among the emergency nurses regarding preparedness of disaster management by their demographic characteristics shows that no significant difference were found on any nurses regarding knowledge about preparedness of disaster management except duration of experience in emergency department $(\mathrm{F}=5.7, \mathrm{P}=0.011)$ and attending previous courses related to disaster preparedness $(\mathrm{t}=2.986$, $\mathrm{P}=0.007$ ) (Table 8). 


\section{Nursing \& Healthcare International Journal}

\begin{tabular}{|c|c|c|c|}
\hline \multirow{2}{*}{ Socio-demographic characteristics } & \multicolumn{2}{|c|}{ Practice score of nurses $(n=22)$} & \multirow{2}{*}{ Significance } \\
\hline & No. & Mean \pm SD & \\
\hline \multicolumn{3}{|l|}{ Age (years) } & \multirow{4}{*}{$\mathrm{F}=0.206 \mathrm{p}=0.815$} \\
\hline $26-35$ & 15 & $56.58 \pm 5.50$ & \\
\hline $36-45$ & 3 & $58.75 \pm 7.60$ & \\
\hline $46 \geq$ & 4 & $56.56 \pm 2.77$ & \\
\hline \multicolumn{3}{|l|}{ Gender } & \multirow{3}{*}{$\mathrm{t}=1.176 \mathrm{p}=0.253$} \\
\hline Female & 14 & $55.89 \pm 5.89$ & \\
\hline Male & 8 & $58.59 \pm 3.50$ & \\
\hline \multicolumn{3}{|l|}{ Marital status } & \multirow{3}{*}{$t=0.912 p=0.373$} \\
\hline Married & 16 & $56.25 \pm 5.57$ & \\
\hline Single & 6 & $58.54 \pm 4.14$ & \\
\hline \multicolumn{3}{|l|}{ Current job } & \multirow{3}{*}{$\mathrm{t}=1.153 \mathrm{p}=0.262$} \\
\hline Nurse & 16 & $56.09 \pm 5.24$ & \\
\hline Head nurse & 6 & $58.96 \pm 5.03$ & \\
\hline \multicolumn{3}{|l|}{ Educational level } & \multirow{4}{*}{$\mathrm{F}=1.417 \mathrm{p}=0.267$} \\
\hline Diploma in nursing & 16 & $55.94 \pm 5.31$ & \\
\hline Technical health institute & 1 & 55 & \\
\hline Bachelor of nursing & 5 & $60.25 \pm 4.37$ & \\
\hline \multicolumn{3}{|c|}{ Duration of experience in emergency department } & \multirow{4}{*}{$\mathrm{F}=1.162 \mathrm{p}=0.334$} \\
\hline Less than 5 years & 2 & $61.88 \pm 0.88$ & \\
\hline $5-10 y e a r s$ & 7 & $55.54 \pm 3.45$ & \\
\hline$>10$ years & 13 & $56.83 \pm 6.05$ & \\
\hline \multicolumn{3}{|l|}{ Attend training related to disaster preparedness } & \multirow{3}{*}{$\mathrm{t}=0.665 \mathrm{p}=0.514$} \\
\hline Yes & 9 & $57.78 \pm 6.64$ & \\
\hline No & 13 & $56.25 \pm 4.18$ & \\
\hline If answer yes & & & \\
\hline \multicolumn{3}{|l|}{ What was duration of course $(n=9)$} & \multirow{5}{*}{$\mathrm{F}=3.958 \mathrm{p}=0.086$} \\
\hline Day & 1 & 61.25 & \\
\hline 3days & 1 & 43.75 & \\
\hline One weak & 6 & $58.54 \pm 4.57$ & \\
\hline More than one weak & 1 & 63.75 & \\
\hline \multicolumn{3}{|l|}{ Number of courses $(n=9)$} & \multirow{3}{*}{$\mathrm{t}=0.224 \mathrm{p}=0.829$} \\
\hline One course & 4 & $57.19 \pm 8.98$ & \\
\hline Three courses & 5 & $58.25 \pm 5.20$ & \\
\hline
\end{tabular}

Table 9: Comparison of practice score among the emergency nurse's regarding preparedness of disaster management by the demographic characteristics

Comparison of practice score among the emergency nurse's regarding preparedness of disaster management by the demographic characteristics shows that no significant statistical differences were found between nurse's practice regarding preparedness of disaster management and their demographic characteristics (Table 9).

\section{Discussion}

The finding of the current study showed that more than two third of the emergency nurses were aged between 25 to 35 years participated in this study, from the researcher point of view this finding is related to newly nursing graduate were appointed to work in the emergency unit. This result is nearly congruent with Ibrahim FAA [3], who revealed that the majority of the nurses were aged below 30 years old, and also this finding is agreed with Zarei V [15], who found that two third of the participants aged between 25 to 44 years old.

Regarding nurses' gender, the present study showed that two third of the emergency nurses were females, this may be due to large number of female nurses were often present in the morning shift, this finding agreed with Nofal A, et al. [16], who found that most of the 


\section{Nursing \& Healthcare International Journal}

participants were females, as well as in the same line with Lakbala P [17], who revealed that more than two third of the participant were females, and also the current finding is in consistent with Zarei V [15], who clarified that two third of the participants were men.

Moreover the finding of this study clarified that below three forth of the studied emergency nurses were had a diploma in nursing and worked in emergency unit in position of nurse staff, this result may be due to increase the number of graduates of nursing diplomas annually and this result is supported by Lakbala $P$ [17], who reported that two third of the participant were had a diploma in nursing.

Concerning years of experience, present study showed that more than half of the studied emergency nurses had more than 10 years of experience in the emergency unit and this finding is in the same line with Nofal A, et al. [16], who revealed that more than half of the participants had a clinical experience of more than 5 years.

The findings of the current study also revealed that more than one third of the studied emergency nurses had attending previous training courses in disaster. This result is partially agreed with Lenox Hill Hospital [18], who found that only a quarter had training courses about disaster, this may be due to hospitals have begun to realize the lack of disaster training courses and have started nursing courses regarding preparedness of disaster to increase nurses awareness regarding disasters due to recurrent disasters in previous periods.

Regarding nurses' knowledge regarding preparedness of disaster management our finding demonstrated that the majority of the studied nurses had unsatisfactory level of knowledge. From the researcher point of view this finding may be related to lack of periodically updated disaster courses and also nurses were not continuously updating their knowledge. Similarly, this study is supported by Ibrahim FAA [3], who showed lack of nurses' knowledge level in disaster preparedness. On the other hand, the present finding is in contrast with [19], who found that the knowledge of the participants was good.

The current study revealed that there was a statistically positive correlation found between nurses' knowledge about preparedness of disaster management and their experience in the emergency department, as well as analysis of the study data revealed that, there was a statistically significant positive association between nurses' knowledge regarding preparedness of disaster management and attending of previous disaster preparedness courses. This finding is supported by Ibrahim FAA [3], who found that knowledge level regarding disaster preparedness showed highly significant differences.

Regarding nurses' practice our findings showed that total practice score regarding preparedness of disaster management among the studied emergency nurses consider satisfactory regarding patient's admission and consider unsatisfactory regarding triage of care, personal protective equipment and infection control measures. The unsatisfactory level of nurses' practice may be due to lake of educational courses regarding preparedness of disaster management, the element of sudden and young age of nurses. Our study finding is agreed with a similar study done by Ibrahim FAA [3], who found that practices of disaster preparedness were below average level. Moreover our finding is in consistent with Sakhar V, et al. [20], who revealed that health care team members had only average practices regarding disaster preparedness.

The present study showed that all emergency nurses done correct practice triage regarding take vital signs and this result is in consistent with Rominski S, et al. [21], who found that the majority of nurses were competent in measuring and recording vital signs once the patient arrives at ER. On the other hand our study finding is in contrast with Mansour $\mathrm{H}$ [22], findings who revealed that lower level of triage knowledge and practice of study group of emergency nurses regarding assessment of vital signs before program implementation.

The present study finding showed that all studied emergency nurses had performed head to toe assessment in correct way. This finding is in consistent with Jones L, et al. [23], who revealed that the majority of emergency nurses had competent performance regarding head to toe assessment. On the other hand the current finding is in contrast with Salem A [24], who clarified that poor level of nurse's competency regarding secondary assessment. The possible explanation for this finding may be due to the availability of resources of this technique.

The present study clarified that all emergency nurses showed satisfactory performance regarding taking complete history from their patients or from the patient's families. From the researcher point of view this result is because taking complete history is considered the first steps to deal with the patient and consider a priority care. This finding is in contrast with Mansour $\mathrm{H}$, et al. [22], who revealed that decreased level of knowledge of the study group and control group regarding primary and 


\section{Nursing \& Healthcare International Journal}

secondary assessment in preprogram implementation, as well as in contrast with Rominski S, et al. [21], who revealed that the lowest nurses knowledge scores were assigned regarding to primary and secondary assessment.

The present study finding showed that emergency nurses had unsatisfactory practice regarding personal protective equipment and infection control measures. From the researcher point of view this result may be due to emergency nurses could belief that their workload is increased by adhering to universal precautions, and this resulted in ignorance of some measures of infection control so that emergency nurses need integration of clearly titled theory and practice teaching courses about personal protective equipments in ER. Finding is in the same line with Abd Elmaksoud A [25], who revealed that the majority of physicians and nurses were not trained on infection control measures.

The current finding was also showed that no one of the studied emergency nurses wore facial masks, and this finding is partially agreed with Vaz K, et al. [26], who revealed that only near half of the studied subjects wore masks.

The finding was also revealed that all of the studied emergency nurses didn't perform recapping needles after using. This result may be due to lack of awareness of nurses about the risk of recapping needles after using and they need specific courses about it, this finding is in the same line with Ali MMM [27], who revealed that all studied nurses use sharp container. On the other hand the current finding is in contrast with Janjua NZ, et al. [28], who revealed that more than half of respondents always recap needles after use.

Our present study showed that no significant difference between nurses' practice regarding preparedness of disaster management and their demographic characteristics, and this current finding is in contrast with Ibrahim FAA [3], who revealed that a highly significant difference of practice level knowledge level regarding disaster preparedness among knowledge level regarding disaster preparedness among.

\section{Conclusion and Recommendation}

This study demonstrates that the level of knowledge and practice was un satisfactory regarding preparedness of disaster management and also the study finding showed that significant difference between nurses' knowledge regarding preparedness of disaster management and duration of experience in emergency department, moreover there was significant difference between nurses" knowledge regarding preparedness of disaster management and attending previous courses related to disaster preparedness, and it can be recommended that emergency nurses need integration of clearly titled theory and practice, teaching courses about disaster and emergency preparedness into nursing curricula are crucial needed and provided in respect to their training preferences.

\section{References}

1. Fung OW, Loke AY, Lai CK (2008) Disaster preparedness among Hong Kong nurses. J Adv Nurs 62(6): 698-703.

2. Haddow G, Bullock J, Coppola DP (2017) Introduction to emergency management. Butterworth-Heinemann, 6th(Edn.), pp: 815.

3. Ibrahim FAA (2014) Nurses knowledge, attitudes, practices and familiarity regarding disaster and emergency preparedness-Saudi Arabia. American Journal of Nursing Science 3(2): 18-25.

4. Warfield C (2008) The Disaster Management Cycle. Disaster Mitigation and Management.

5. Hochrainer S (2009) Assessing the Macroeconomic Impacts of Natural Disasters: Are There Any?" Policy Research Working Paper 4968 (Washington: World Bank).

6. Eshghi K, Larson RC (2008) Disasters: lessons from the past 105 years. Disaster Prevention and Management: An International Journal 17(1): 62-82.

7. Abd Elmaksoud A (2014) Assessment of infection control awareness and commitment among physicians and nurses working in surgical departments in Benha university hospital, master thesis, Faculty of medicine, Benha university.

8. Baack S, Alfred D (2013) Nurses' preparedness and perceived competence in managing disasters. J Nurs Scholarsh 45(3): 281-287.

9. Sunders (2007) Emergency Nursing Core Curriculum, $6^{\text {th }}$ (Edn.), (Chapter 39) Disaster Preparedness and Response, United States of America, pp: 955-969.

10. Brunner, Suddarth's (2010) Text book of MedicalSurgical Nursing, $12^{\text {th }}$ (Edn.), (Chapter 72) Terrorism, Mass Casualty, and Disaster Nursing, pp: 2195. 


\section{Nursing \& Healthcare International Journal}

11. Kumagai D (2013) Medical-Surgical Nursing: Concept and Practice, 2nd (Edn.), (Chapter44), Newyork, pp: 997-1018.

12. Brink, Wood \& Munhall (2012) Advanced Design in Nursing Research, $2^{\text {nd }}($ Edn.), Thousand Oaks, Calif: Sage.

13. Altun I, Cinar DN, Barin C0 (2010) Practice techniques for administration of injections: Impact of lecture based interactive workshops on training of nurses, Pakistan Journal of Medical Science 26(1): 152-157.

14. Youssef W, Ali NS, Samy R (2014) Critical Care Nurses' Knowledge and Practice Regarding Administration of Selected Positive Inotropics at Cairo University Hospitals. Critical Care 4(2).

15. Zarei V (2016) Emergency preparedness of hospitals in Tehran and its relation with crisis management measures. International Journal of Medical Research \& Health Sciences 5(9): 471-478.

16. Nofal A, Alfayyad I, Khan A, Al Aseri Z, Abu-Shaheen A (2018) Knowledge, attitudes, and practices of emergency department staff towards disaster and emergency preparedness at tertiary health care hospital in central Saudi Arabia. Saudi Med J 39(11): 1123-1129.

17. Lakbala P (2015) Hospital Workers Disaster Management and Hospital Nonstructural: A Study in Bandar Abbas, Iran. Glob J Health Sci 8(4): 221-226.

18. Lenox Hill Hospital (2016) Perceptions of hospital medical personnel on disaster preparedness. New York, pp: 1938.

19. Shabbir R, Afzal M, Sarwer H, Gilani SA, Waqas A (2017) Nurses Knowledge and Practices Regarding Disasters Management and Emergency Preparedness.

20. Sakhar V, Waghmare S, Joshi SG (2016) Knowledge and attitude regarding disaster preparedness among the health care team members in selected hospitals of pune city. International Journal of Recent Scientific Research Research 7(5): 11252-11257.

21. Rominski S, Bell SA, Oduro G, Ampong P, Oteng R (2014) The Implementation of The South Africa Triage Score(SATS)In an Urban Teaching Hospital, Ghana. Africa Journal Emergency Medicine 4(2): 7175.

22. Mansour H, ELS, ELS (2014) Effect of implementing triage training competencies on newly graduated nurses working in emergency hospital. Thesis. Mansoura University, Faculty of Nursing, pp: 71.

23. Jones L, Touslson K, McConnell L (2009) Responding to Trauma: Your Priorities in The First Hour. Critical Care Nursing Journal 4(1): 35-41.

24. Salem A (2006) Development of Nursing Practice Standards for Emergency Trauma Patients .MSCN Thesis Alexandria University, Faculty of Nursing, pp: 83-92.

25. Abd Elmaksoud A (2014) Assessment of infection control awareness and commitment among physicians and nurses working in surgical departments in Benha university hospital, master thesis, Faculty of medicine, Benha university.

26. Vaz K, McGrowder D, Alexander-Lindo R, Gordon L, Brown P, et al. (2010) Knowledge, awareness and compliance with universal precautions among health care workers at the University Hospital of the West Indies, Jamaica. Int J Occup Environ Med 1(4): 171181.

27. Ali MMM (2015) Critical Care Patient's Safety: Assessment of Nurses Perception, Knowledge, and Practice. Faculty of Nursing, Mansoura University (Critical and Emergency Unit), pp: 50.

28. Janjua NZ, Khan MI, Mahmood B (2010) Sharp injurie $s$ and their determinants among health care workers at first-level care facilities in Sindh Province, Pakistan. Trop Med Int Health 15(10): 1244-1251. 